\title{
Chemical oxidation of fish canning wastewater by Fenton's reagent
}

\author{
Raquel O. Cristóvão ${ }^{\mathrm{a}, *}$, Cristiana Gonçalves ${ }^{\mathrm{a}}$, Cidália M. Botelho ${ }^{\mathrm{a}}$, Ramiro J.E. Martins ${ }^{\mathrm{a}, \mathrm{b}}$, \\ Rui A.R. Boaventura ${ }^{a}$
}

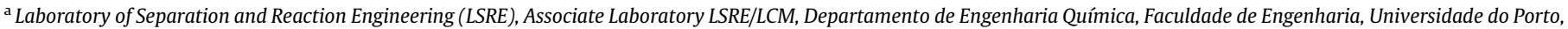
Rua do Dr. Roberto Frias, Porto 4200-465, Portugal

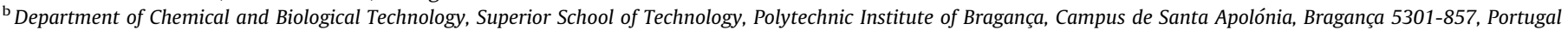

\section{A R T I C L E I N F O}

\section{Article history:}

Received 31 October 2013

Received in revised form 16 December 2013

Accepted 27 December 2013

\section{Keywords:}

Fish canning wastewater

Wastewater treatment

Fenton's reagent

Chemical oxidation

Box-Behnken design

Optimization

\begin{abstract}
A B S T R A C T
The fish canning industry generates large volumes of wastewater for which the treatment is particularly difficult due to the high content of organic matter and salts and to the significant amount of oil and grease they present.

In this work, a closed jacketed batch reactor was used to study the feasibility of applying a Fenton reaction step after an activated sludge biological treatment. For this purpose and in order to find optimal conditions, a $3^{3}$ Box-Behnken full factorial design was used. The predicted optimum value (63\% DOC degradation) was found for hydrogen peroxide concentration of $1558 \mathrm{mg} / \mathrm{L}$, iron concentration of $363 \mathrm{mg} / \mathrm{L}$ and $\mathrm{pH} 3.2$.
\end{abstract}

(๖ 2014 Elsevier Ltd. All rights reserved.

\section{Introduction}

Fish-processing industry consumes huge quantities of water, producing large amounts of wastewaters, from factory cleaning and raw materials washing [1]. These effluents have quite a high organic load and also high levels of salinity. Cooking effluents from fish canning industry also show a marked organic matter load. The high salinity $\left(\mathrm{Na}^{+}, \mathrm{Cl}^{-}, \mathrm{SO}_{4}{ }^{2-}\right)$ is caused both by raw material and brine, used in the process [2]. The level of total soluble and suspended chemical oxygen demand (COD) varies largely between factory and fish type [3]. It is also known a frequent change of products to be treated, with variation in flow rates and composition, which implies changes in wastewater characteristics. These variable operating conditions difficult the planning of a common treatment plant for all of the wastewaters produced in a single unit. A treatment process suitable to treat or even valorize and recycle this wastewater must be found, or it can be difficult the evolution of the small and medium size units, since they often cannot afford a plan for managing their effluents.

Biological treatment is the most common process used to treat organics-containing wastewaters [4]. The biological processes are frequently employed since they are more economic and environmental friendly, using optimized natural pathways to actually destroy pollution, not only transform it into another form [5].

\footnotetext{
* Corresponding author. Tel.: +351 22508 1686; fax: +35122 5081674

E-mail address: raquel.cristovao@fe.up.pt (R.O. Cristóvão).
}

However, some refractory compounds persist after the biological treatment and chemical oxidative processes arise as good methods to treat the remaining recalcitrant organic matter. The Fenton reagent $\left(\mathrm{Fe}^{2+} / \mathrm{H}_{2} \mathrm{O}_{2}\right)$ is currently accepted as one of the most effective methods for the oxidation of organic pollutants [6]. Oxidation of organic substrates by Fenton's reagent has been studied since 1894 [7]. It is currently known that the efficiency of the Fenton's reaction depends mainly on $\mathrm{H}_{2} \mathrm{O}_{2}$ concentration, $\mathrm{Fe}^{2+}$ / $\mathrm{H}_{2} \mathrm{O}_{2}$ ratio, $\mathrm{pH}$ and reaction time. The initial concentration of the pollutants and their characteristics, as well as temperature, also have a substantial influence on the overall efficiency [6].

The experimental design and response surface methodology (RSM) are useful statistical techniques to identify and optimize factors that influence a particular process, through a reduced number of experiments to be performed. Additionally, the relative significance of the factors and possible synergistic or antagonistic interactions that may exist between them can be evaluated [8]. This multivariate technique fits the experimental data to a theoretical model through a response function, estimating this way the model coefficients. The adequacy of the model is evaluated by the coefficient of determination $R^{2}$.

The most common design of RSM is Box-Behnken design (BBD) $[8,9]$, which is well suited for fitting a quadratic surface, since it considers three levels per factor and fills in the combinations of center and extreme levels in which the optimal conditions for an experiment are found [10,11]. This design has been widely applied in the optimization of several treatment processes [12-14] because of its reasoning strategy and excellent outcomes. 
Advanced oxidation of fish canning wastewaters by Fenton's reagent has not been yet reported in the literature. Therefore, the major objective of this study is to investigate the total or partial mineralization and the reduction of recalcitrant organic compounds by Fenton's reagent of a previously biologically treated fish canning wastewater, in terms of dissolved organic carbon (DOC), with the aim to meet the emission limit values for discharge into water bodies established by Decree-Law No. 236/98 (COD $\leq 150 \mathrm{mg} / \mathrm{L}$ ). The effects of initial $\mathrm{pH}, \mathrm{Fe}(\mathrm{II})$ and $\mathrm{H}_{2} \mathrm{O}_{2}$ concentrations on the reaction were investigated by using a $3^{3}$ Box-Behnken full factorial design with RSM. Optimal values of the operating parameters maximizing DOC removals were determined.

\section{Materials and methods}

\section{Fish-processing wastewater}

The clarified fish processing wastewater with a final dissolved organic carbon (DOC) of about $50 \mathrm{mg} / \mathrm{L}$, a chemical oxygen demand (COD) of about $220 \mathrm{mg} / \mathrm{L}$, a biochemical oxygen demand $\left(\mathrm{BOD}_{5}\right)$ of about $0.8 \mathrm{mg} / \mathrm{L}$, a conductivity of $30-40 \mathrm{mS} / \mathrm{cm}$ and a $\mathrm{pH}$ between 7 and 8 was obtained after a biological treatment and used for chemical oxidation, with Fenton's reagent.

\section{Fenton trials}

Chemical oxidation was performed in a closed jacketed batch reactor ( $1 \mathrm{~L}$ capacity), which contained $500 \mathrm{~mL}$ of the previously biologically treated effluent, for $1 \mathrm{~h}$. The reactor operated under constant stirring, accomplished through a magnetic bar and a Falc magnetic stirrer. The temperature of the reaction mixture was kept constant at $33^{\circ} \mathrm{C}$ by coupling the reactor to a thermostatic bath. Reagents employed in the oxidation process were $\mathrm{FeSO}_{4} \cdot 7 \mathrm{H}_{2} \mathrm{O}$ (Panreac) and $\mathrm{H}_{2} \mathrm{O}_{2}$ (30 wt.\%, from Riedel-de Haën). The pH in the reaction mixture was adjusted to the desired value using $\mathrm{H}_{2} \mathrm{SO}_{4}$ (95-97\%, Fluka).

Before each run, the effluent was put into the reactor, and the temperature stabilized. The catalyst (iron sulphate) was introduced after $\mathrm{pH}$ adjustment to avoid iron precipitation. Time zero of the runs was defined as the moment of hydrogen peroxide solution addition. The reaction was stopped after $1 \mathrm{~h}$ by reducing $\mathrm{H}_{2} \mathrm{O}_{2}$ with $\mathrm{Na}_{2} \mathrm{SO}_{3}$ (Merck) in excess. Any remaining sulphite was oxidized by bubbling $\mathrm{O}_{2}$. To measure the solution temperature and $\mathrm{pH}$, a thermocouple and a pH electrode (WTW, Sentix 41 model), connected to a pH-meter from WTW (model inolab pH Level 2), were used, respectively.

\section{Analytical methods}

The DOC was determined by catalytic oxidation followed by quantification of the $\mathrm{CO}_{2}$ formed through non-dispersive infra-red spectrometry (NDIR), as described in Method No. 5310 D of the Standard Methods for the Examination of Water and Wastewater [15]. For that, a Shimadzu 5000A Total Organic Carbon (TOC) analyzer was used. DOC values reported represent the average of at least two measurements; in most cases each sample was injected three times, validation being performed by the apparatus only if coefficient of variation (CV) was smaller than $2 \%$.

Standard methods for the examination of wastewater [15] were also adopted for the measurement of $\mathrm{COD}$ and $\mathrm{BOD}_{5}$ (methods $5220 \mathrm{C}$ and $5210 \mathrm{~B}$, respectively).

\section{Factorial design}

A $3^{3}$ Box-Behnken full factorial design, including three replicates at central point, was carried out in order to analyze the influence of the factors $\mathrm{pH}, \mathrm{Fe}(\mathrm{II})$ and $\mathrm{H}_{2} \mathrm{O}_{2}$ concentrations on the DOC abatement of a fish canning wastewater by Fenton's reaction. However, first of all, in order to decide the factor values to study, the stoichiometric $\mathrm{H}_{2} \mathrm{O}_{2}$ requirements for sample degradation were determined taking into account the COD value. After this, the initial $\mathrm{Fe}(\mathrm{II})$ concentration was established by varying the molar $[\mathrm{Fe}(\mathrm{II})] /\left[\mathrm{H}_{2} \mathrm{O}_{2}\right]$ ratio from $1 / 2$ to $1 / 65$. Nevertheless, perhaps because of the high variability of the real wastewater that is being studied, the optimum conditions determination was not easy, but it seemed that there was a trend toward higher values of $\mathrm{H}_{2} \mathrm{O}_{2}$. So, it was decided to start with a Box-Behnken factorial design only with 2 factors $\left(\mathrm{H}_{2} \mathrm{O}_{2}\right.$ and $\mathrm{Fe}(\mathrm{II})$ concentrations) to analyze the results trend. With that help and knowing the normal $\mathrm{pH}$ values range for Fenton's reagent wastewater treatment [16,17], a BoxBehnken full factorial design with 3 factors and 3 levels was done later, in order to define the reaction optimum conditions and to analyze the factors influence. Each independent variable was coded at three levels between -1 (low level), 0 (middle point) and +1 (high level). The coding of the variables was done by Eq. (1) [18]:

$x_{i}=\frac{X_{i}-X_{z}}{\Delta X_{i}}, \quad i=1,2,3, \ldots, k$

where $x_{\mathrm{i}}$, is the dimensionless value of an independent variable, $X_{i}$ is the real value of an independent variable, $X_{z}$ is the real value of an independent variable at the center point and $\Delta X_{i}$ is the step change of the real value of the variable $i$ corresponding to a variation of a unit for the dimensionless value of the variable $i$. The levels of each factor are listed in Table 1. Table 2 gives the experimental design matrix.

The experimental Box-Behnken design, analysis of variance (ANOVA) and 3D response surface were carried out using the software Statistica v12.0 (Statsoft Inc.). Eq. (2) describes the regression model of the present system, which includes the interaction terms:

$$
\begin{aligned}
Y= & \beta_{0}+\beta_{1} x_{1}+\beta_{2} x_{2}+\beta_{3} x_{3}+\beta_{12} x_{1} x_{2}+\beta_{13} x_{1} x_{3}+\beta_{23} x_{2} x_{3} \\
& +\beta_{11} x_{1}^{2}+\beta_{22} x_{2}^{2}+\beta_{33} x_{3}^{2}
\end{aligned}
$$

where $Y$ is the predicted response, i.e. the DOC removal; $x_{1}, x_{2}$ and $x_{3}$ are the coded levels of the independent factors $\left(\mathrm{H}_{2} \mathrm{O}_{2}\right.$ concentration, $\mathrm{Fe}(\mathrm{II})$ concentration and $\mathrm{pH}$, respectively). The regression coefficients are: $\beta_{0}$ the intercept term; $\beta_{1}, \beta_{2}$ and $\beta_{3}$ the linear coefficients; $\beta_{12}, \beta_{13}, \beta_{23}$ the interaction coefficients and $\beta_{11}$, $\beta_{22}, \beta_{33}$ the quadratic coefficients. The model evaluates the effect of each independent factor on the response.

\section{Results and discussion}

The characteristics of the biologically treated wastewater show the high recalcitrant nature of the organic compounds present in it, which is reflected by its very low $\mathrm{BOD}_{5} / \mathrm{COD}$ ratio $(<0.005)$. For treatment of such a wastewater, an advanced oxidation process, such as Fenton's reagent, seems to be a suitable option.

The performance and optimization of Fenton treatment was investigated applying a Box-Behnken full factorial design with three factors: hydrogen peroxide concentration, iron concentration and

Table 1

Factor levels for a $3^{3}$ Box-Behnken factorial design.

\begin{tabular}{llrrr}
\hline \multirow{2}{*}{ Factors } & Parameters & \multicolumn{3}{c}{ Coded level } \\
\cline { 3 - 5 } & & \multicolumn{1}{c}{+1} & \multicolumn{1}{c}{0} & -1 \\
\hline$X_{1}$ & {$\left[\mathrm{H}_{2} \mathrm{O}_{2}\right](\mathrm{mg} / \mathrm{L})$} & 2000 & 1050 & 100 \\
$X_{2}$ & {$[\mathrm{Fe}(\mathrm{II})](\mathrm{mg} / \mathrm{L})$} & 400 & 225 & 50 \\
$X_{3}$ & $\mathrm{pH}$ & 3.5 & 3.0 & 2.5 \\
\hline
\end{tabular}


Table 2

Box-Behnken design matrix with experimental results and predicted values for fish canning wastewater DOC oxidation.

\begin{tabular}{|c|c|c|c|c|c|}
\hline \multirow[t]{2}{*}{ Run } & \multicolumn{3}{|c|}{ Factors } & \multicolumn{2}{|c|}{ DOC removal (\%) } \\
\hline & $X_{1}(\mathrm{mg} / \mathrm{L})$ & $\mathrm{X}_{2}(\mathrm{mg} / \mathrm{L})$ & $X_{3}$ & Actual value & Predicted value \\
\hline 1 & 100 & 50 & 2.5 & 23.9 & 20.0 \\
\hline 2 & 100 & 50 & 3.0 & 22.6 & 24.2 \\
\hline 3 & 100 & 50 & 3.5 & 5.0 & 12.2 \\
\hline 4 & 100 & 225 & 2.5 & 41.2 & 38.9 \\
\hline 5 & 100 & 225 & 3.0 & 46.3 & 46.7 \\
\hline 6 & 100 & 225 & 3.5 & 42.7 & 38.2 \\
\hline 7 & 100 & 400 & 2.5 & 26.5 & 37.0 \\
\hline 8 & 100 & 400 & 3.0 & 53.9 & 48.2 \\
\hline 9 & 100 & 400 & 3.5 & 46.6 & 43.3 \\
\hline 10 & 1050 & 50 & 2.5 & 26.6 & 24.7 \\
\hline 11 & 1050 & 50 & 3.0 & 33.7 & 31.3 \\
\hline 12 & 1050 & 50 & 3.5 & 26.4 & 21.7 \\
\hline 13 & 1050 & 225 & 2.5 & 50.1 & 45.7 \\
\hline 14 & 1050 & 225 & 3.0 & 49.6 & 55.8 \\
\hline 15 & 1050 & 225 & 3.5 & 49.8 & 49.8 \\
\hline 16 & 1050 & 400 & 2.5 & 48.0 & 45.8 \\
\hline 17 & 1050 & 400 & 3.0 & 65.4 & 59.4 \\
\hline 18 & 1050 & 400 & 3.5 & 51.1 & 56.9 \\
\hline 19 & 2000 & 50 & 2.5 & 10.3 & 18.1 \\
\hline 20 & 2000 & 50 & 3.0 & 29.2 & 27.1 \\
\hline 21 & 2000 & 50 & 3.5 & 21.5 & 19.9 \\
\hline 22 & 2000 & 225 & 2.5 & 44.4 & 41.1 \\
\hline 23 & 2000 & 225 & 3.0 & 52.0 & 53.7 \\
\hline 24 & 2000 & 225 & 3.5 & 53.4 & 50.0 \\
\hline 25 & 2000 & 400 & 2.5 & 43.5 & 43.3 \\
\hline 26 & 2000 & 400 & 3.0 & 62.7 & 59.3 \\
\hline 27 & 2000 & 400 & 3.5 & 54.8 & 59.2 \\
\hline 28 & 1050 & 225 & 3.0 & 54.8 & 55.8 \\
\hline 29 & 1050 & 225 & 3.0 & 47.1 & 55.8 \\
\hline
\end{tabular}

$\mathrm{pH}$. The results from the 29 experiments are presented in Table 2. Using the experimental data, the second order polynomial model (Eq. (2)) was fitted to these results and obtained in terms of coded factors:

$$
\begin{aligned}
Y= & -247.7-0.001 x_{1}+0.1 x_{2}+183.8 x_{3}-32.36 x_{3}^{2} \\
& +0.005 x_{1} x_{3}+0.04 x_{2} x_{3}
\end{aligned}
$$

The DOC oxidation results predicted by the model presented above, at each experimental point, are presented in Table 2. The statistical significance of the polynomial model for the experimental response was evaluated by ANOVA. According to the ANOVA results (Table 3 ), the quadratic model, including linear interactions, fitted adequately to the experimental data giving a coefficient of determination, $R^{2}$, of 0.9053 .

Table 3

Analysis of variance (ANOVA) for the fitted quadratic polynomial model for optimization of DOC oxidation of a fish canning wastewater by Fenton's reagent.

\begin{tabular}{llllll}
\hline Source & Sum of squares $(\mathrm{SS})$ & $\mathrm{df}^{\mathrm{a}}$ & Mean square $(\mathrm{MS})$ & $F$-value & $p$-Value \\
\hline$(1) x_{1}\left(\mathrm{~L}^{\mathrm{b}}\right)$ & 221.2 & 1 & 221.2 & 6.9 & 0.0168 \\
$x_{1}\left(\mathrm{Q}^{\mathrm{C}}\right)$ & 211.4 & 1 & 211.4 & 6.6 & 0.0191 \\
$(2) x_{2}(\mathrm{~L})$ & 3564.5 & 1 & 3564.5 & 110.6 & 0.0000 \\
$x_{2}(\mathrm{Q})$ & 724.6 & 1 & 724.6 & 22.5 & 0.0001 \\
$(3) x_{3}(\mathrm{~L})$ & 75.2 & 1 & 75.2 & 2.3 & 0.1429 \\
$x_{3}(\mathrm{Q})$ & 435.1 & 1 & 435.1 & 13.5 & 0.0016 \\
$1 \mathrm{~L}$ by 2L & 50.0 & 1 & 50.0 & 1.6 & 0.2279 \\
$1 \mathrm{~L}$ by 3L & 69.1 & 1 & 69.1 & 2.1 & 0.1593 \\
2L by 3L & 149.8 & 1 & 149.8 & 4.7 & 0.0441 \\
Error & 612.1 & 19 & 32.2 & & \\
Total SS & 6462.7 & 28 & & & \\
\hline
\end{tabular}

Note: $R^{2}=0.9053 ;$ adj $R^{2}=0.8604$.

a df: degrees of freedom.

b L: linear.

c Q: quadratic.

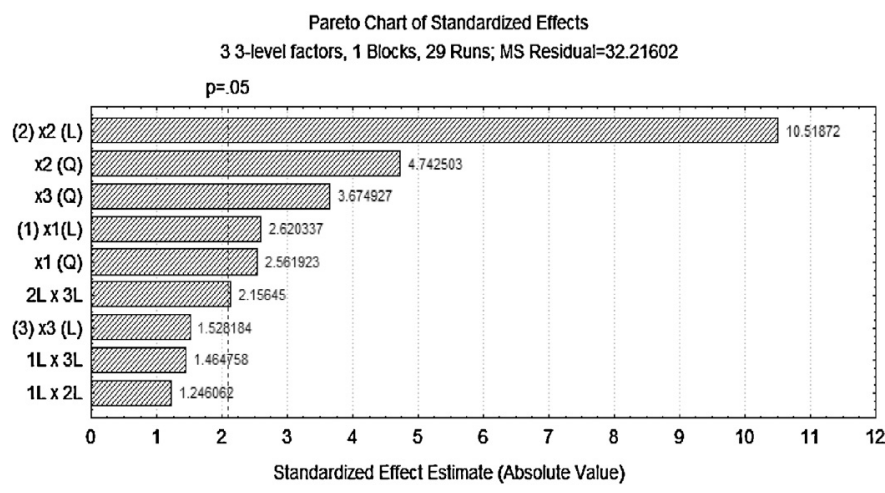

Fig. 1. Pareto chart of standardized effects for $3^{3}$ Box-Behnken factorial design. (1) $\mathrm{H}_{2} \mathrm{O}_{2}$ concentration; (2) $\mathrm{Fe}(\mathrm{II})$ concentration; (3) $\mathrm{pH}$.

The regression coefficients and the interaction between each independent factor can be considered statistically significant for $p$ values lower than 0.05 , with $95 \%$ of confidence interval. The Pareto chart also displays the statistically relevant effect of each factor on the response and it is a practical mode to view the results. These are sorted from the largest to the smallest, and the effects to the right of the divisor line are significant. Thus, according to the ANOVA results (Table 3 ) and to the Pareto chart (Fig. 1), it is possible to observe that the linear and quadratic terms of iron concentration $\left(x_{2}\right)$ are the factors that most affect the reduction of DOC of the fish canning wastewater in study, by Fenton's reagent. However, both terms of hydrogen peroxide concentration $\left(x_{1}\right)$ and the quadratic term of $\mathrm{pH}\left(x_{3}\right)$ also have an effect on the reaction whilst the interaction between the three factors and the linear term of $\mathrm{pH}$ do not affect the oxidative process.

The effects of the independent factors and their interaction on the oxidation are also represented by RSM, with which is also possible to predict the response and to determine the optimum values of the parameters affecting the reaction. The response surface plots (Fig. 2) show the DOC removal as function of two factors, whilst the third was kept at a constant level. By these plots is then possible to clearly observe that the optimum conditions for obtaining the maximum degradation are within the experimental ranges tested.

Particularly, the surface plots show the increase of DOC degradation with the increase of iron concentrations. Plots 2a and 2c (Fig. 2) clearly show that the DOC degradation by Fenton's reagent was sensitive even to small alterations of iron concentration. The DOC degradation of the fish canning wastewater was increased up to a critical iron concentration and thereafter the DOC degradation decreased. The existence of an optimal iron concentration is explained by the reaction of the excess of iron ions with the hydroxyl radical (Eq. (4)), thereby decreasing the concentration of radicals available and limiting the oxidation of organic compounds [19].

$\mathrm{HO}^{\bullet}+\mathrm{Fe}^{2+} \rightarrow \mathrm{OH}^{-}+\mathrm{Fe}^{3+}$

Furthermore, the high concentrations of iron are not desirable for two practical reasons: the reagent cost and the need of iron sludge treatment, which means also higher costs [20].

As it can be seen from plot $2 b$ (Fig. 2), the hydrogen peroxide concentration and the $\mathrm{pH}$ did not seem to play an important role on DOC abatement, in the study ranges. But it is possible to observe the existence of an optimum hydrogen peroxide concentration, which is justified by parallel reactions between the $\mathrm{H}_{2} \mathrm{O}_{2}$ in excess and the hydroxyl radical, generating $\mathrm{HO}_{2} \cdot$ species with a lower oxidation potential [21]. 


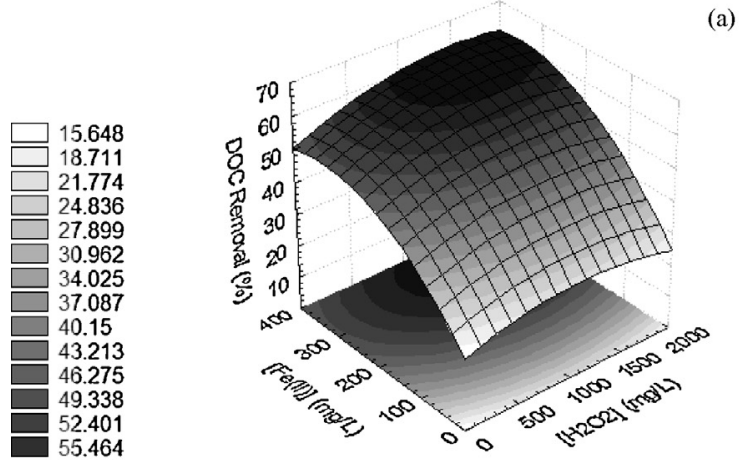

(a)
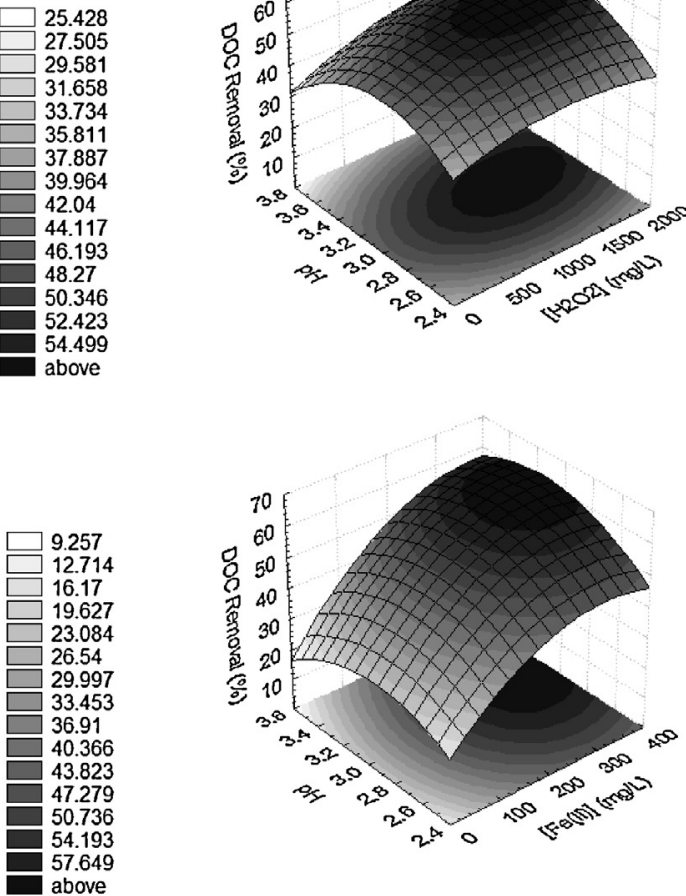

(c)

Fig. 2. Response surface plots for $D O C$ removal of a fish canning wastewater by Fenton's reagent as a function of: (a) $\mathrm{H}_{2} \mathrm{O}_{2}$ and $\mathrm{Fe}$ (II) concentration at pH 3 ; (b) $\mathrm{H}_{2} \mathrm{O}_{2}$

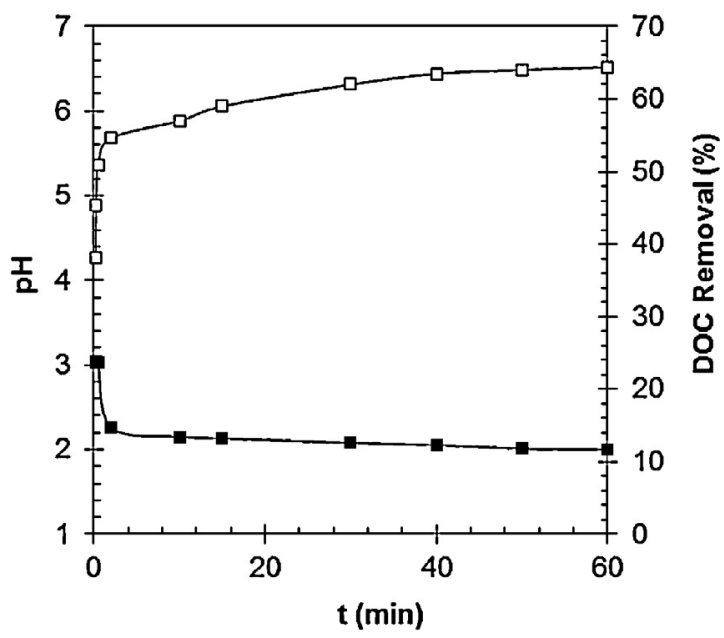

Fig. 3. Time course of pH variation ( $\square$ ) and DOC removal ( $\square$ ). Each point represents the average of three replicates (S.D. $<10 \%$ of the mean).
The adequacy of the proposed model (Eq. (3)) for organic matter oxidation of pre-treated fish canning wastewaters by Fenton's reagent was evaluated at the optimum operating conditions. According to the model the optimum conditions were: hydrogen peroxide concentration of $1558 \mathrm{mg} / \mathrm{L}$, iron concentration of $363 \mathrm{mg} / \mathrm{L}$ and $\mathrm{pH} 3.2$, predicting above 63\% DOC reduction. Under these optimal conditions, new experiments were conducted in triplicate and a DOC abatement of $64.4 \%$ was achieved, which is in good agreement with the oxidation predicted by the model. Furthermore, for the entire range of the tested factors, the experimental results are very close to the predicted values obtained from the model.

The optimum $\mathrm{Fe}(\mathrm{II})$ concentration attained, emphasizes the need of sludge treatment, which brings associated costs. The optimum iron concentration found $(363 \mathrm{mg} / \mathrm{L}$ ) is a relatively high concentration and for effluent discharge, the $\mathrm{pH}$ value must be adjusted for the range of 6-9, according to the Portuguese legislation (Decree-Law No. 236/98). The required pH adjustment will cause the production of a significant quantity of chemical sludge. Knowing that the iron emission limit value for discharge is $2 \mathrm{mg} / \mathrm{L}$, a concentration of $361 \mathrm{mg} / \mathrm{L}$ of $\mathrm{Fe}^{3+}$ stays free to (according to $\mathrm{Fe}^{3+}$ speciation diagram) totally precipitate as $\mathrm{Fe}(\mathrm{OH})_{3}$ when the $\mathrm{pH}$ is increased to the maximum value allowed to discharge. This precipitate needs further treatment, but the costs involved depend not only on the treatment sequence (sedimentation, thickening, drying) but also on transportation and landfilling costs.

The observed maximum of $\mathrm{DOC}$ reduction at $\mathrm{pH} 3.2$ is in agreement with the values found in the literature for other wastewaters treated by Fenton's reagent [20,22,23]. The high amounts of reagents necessary to obtain some organic matter removal can be explained firstly by the nature of the effluent, which has already been biologically treated and contains predominantly recalcitrant matter and then, by the high salt concentration, which decreases the process efficiency due to chloride ions, that are able to trap hydroxyl radicals, producing hypochlorous acid precursors or to react with the hydroxyl radicals producing less reactive radicals [24]. So the concentration of Fenton's reagent employed must be enough to overcome the restrictions imposed by the salinity.

Fig. 3 shows the DOC removal by Fenton oxidation and the corresponding $\mathrm{pH}$ variation over time, under the optimal conditions found. It is possible to observe that the decomposition was performed in two stages: via a rapid first-stage (up to $2 \mathrm{~min}$ ) followed by a slow second-stage (from 2 min to end). This profile of degradation was found in literature and had been recognized in various Fenton processes [25-28]. During the first 2 min of the reaction, rapid pollutant degradation is attributed to high ${ }^{\circ} \mathrm{OH}$ concentrations, as a result of greater amounts of $\mathrm{Fe}^{2+}$ catalyst in solution that reacts with $\mathrm{H}_{2} \mathrm{O}_{2}$. At the second stage, $\mathrm{Fe}^{3+}$ ions were combined with $\mathrm{H}_{2} \mathrm{O}_{2}$ to produce weaker oxidant radicals compared to ${ }^{\circ} \mathrm{OH}$, in addition to their slower rate of production [27].

The $\mathrm{pH}$, which was not corrected during each experiment, had a similar profile to the DOC abatement but in the reverse direction, decreasing until the end. A detailed kinetic study is very difficult to perform for Fenton process in this kind of effluents due to complexity of chemical compounds formed as intermediates during the reaction [29] and to the high initial reaction rate. However, it was attempted to fit the experimental results to a parallel decay kinetic model (Eq. (5)), which simulates the two different stages observed:

$D O C_{t}=C_{0} \cdot p \cdot \exp \left(-k_{1} \cdot t\right)+C_{0} \cdot(1-p) \cdot \exp \left(-k_{2} \cdot t\right)$

where $D O C_{t}$ is the DOC concentration $(\mathrm{mg} / \mathrm{L})$ at time $t, C_{0}$ is the DOC initial concentration $(49.43 \mathrm{mg} / \mathrm{L}), p$ represents a fraction of $C_{0}, k_{1}$ and $k_{2}$ are the decay kinetic constants and $t$ is the time (min). 


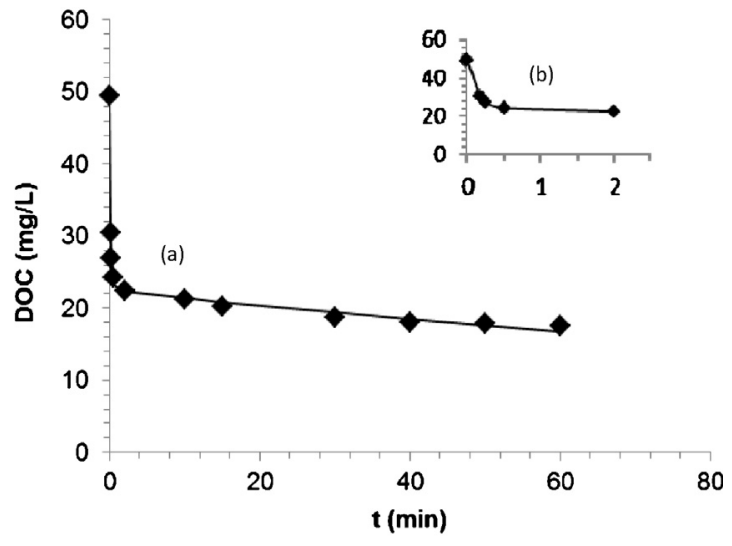

Fig. 4. (a) Comparison of experimental $(\bullet)$ and simulated (continuous line) time courses of DOC removal by Fenton oxidation of a fish canning wastewater previously biologically treated, with initial DOC concentration of $49.43 \mathrm{mg} / \mathrm{L}$. (b) Scale amplification of (a).

Using the program Fig. P-The Scientific Fig. Processor, v. 2.98, Biosoft, the kinetic constants of the model were achieved, leading to the model present in the Eq. (6) with a coefficient of correlation $R^{2}$ of 0.997 .

$D O C_{t}=22.47 \exp (-0.005 t)+26.96 \exp (-7.04 t)$

In order to evaluate the adequacy of the proposed model for the kinetics of DOC removal of a fish canning wastewater previously biologically treated by Fenton's oxidation, the time course calculated by the kinetic model was compared with the experimental one (Fig. 4). The close correlation between the predicted and the experimental results seems to support the reliability of the established model.

\section{Conclusions}

The overall results of this study indicate that the application of Fenton's reagent is a feasible method to partially treat fish canning wastewaters, allowing achieve a satisfactory decrease of DOC.

Therefore, the combination of a biological treatment of a fish canning wastewater with a chemical oxidation by Fenton's reagent gave an effluent that in terms of organic matter content can be directly discharged into water bodies or sewerage systems (reaching a value of $20 \mathrm{mg} / \mathrm{L}$ of DOC, that, by the initial COD vs DOC proportion and considering that practically only the organic matter is removed by Fenton's reagent treatment, corresponds to a COD value of approximately $90 \mathrm{mg} / \mathrm{L}$, which is below the emission limit value $(150 \mathrm{mg} / \mathrm{L}))$. Just to note: since during the Fenton process the wastewater is strongly acidic, to directly discharge it to environment, the $\mathrm{pH}$ value should be increased to the emission limit values ( $\mathrm{pH}$ 6-9) established by Decree-Law No. 236/98.

\section{Acknowledgments}

This work is partially supported by project PEst-C/EQB/LA0020/ 2011, financed by FEDER through COMPETE - Programa Operacional Factores de Competitividade and by FCT - Fundação para a Ciência e a Tecnologia and by ValorPeixe - Valorização de Subprodutos e Águas Residuais da Indústria de Conservas de Peixe, project in co-promotion I\&DT QREN, $\mathrm{n}^{\circ} 13634$, financed by FEDER through POFC - Programa Operacional Factores de Competitividade for which the authors are thankful. The authors also wish to thank the cannery in study for wastewater samples. Raquel $\mathrm{O}$.
Cristóvão thanks FCT for the Pos-doc Scholarship (SFRH/BPD/ 81564/2011).

\section{References}

[1] J. Lim, T. Kim, S. Hwang, Treatment of fish-processing wastewater by co-culture of Candida rugopelliculosa and Brachionus plicatilis, Water Res. 37 (2003) 2228-2232.

[2] E. Garcia-Sanda, F. Omil, J. Lema, Clean production in fish canning industries: recovery and reuse of selected wastes, Clean Technol. Environ. Policy 5 (2003) 289-294.

[3] P. Chowdhury, T. Viraraghavan, A. Srinivasan, Biological treatment processes for fish processing wastewater-a review, Bioresource Technol. 101 (2010) 439-449.

[4] A. Christensen, M.D. Gurol, T. Garoma, Treatment of persistent organic compounds by integrated advanced oxidation processes and sequential batch reactor. Water Res. 43 (2009) 3910-3921.

[5] A.Z. Gotvajn, J. Zagorc-Koncan, Combination of Fenton and biological oxidation for treatment of heavily polluted fermentation waste broth, Acta Chim. Slov. 52 (2005) 131-137.

[6] K. Barbusinski, Fenton reaction-controversy concerning the chemistry, Ecol. Chem. Eng. S. 16 (2009) 347-358.

[7] H.B. Dunford, Oxidations of iron(II)/(III) by hydrogen peroxide: from aquo to enzyme, Coord. Chem. Rev. 233 (2002) 311-318.

[8] G.E.P. Box, W.G. Hunter, J.S. Hunter, Statistics for Experimenters: An Introduction to Design, Data Analysis, and Model Building, John Wiley \& Sons, 1978.

[9] A.M. Dean, D.T. Voss, Design and Analysis of Experiments, Springer-Verlag, Inc, New York, 1999, pp. 547-558.

[10] G.E.P. Box, D.W. Behnken, Some new three level designs for the study of quantitative variables, Technometrics 2 (1960) 455-475.

[11] G. Hanrahan, K. Lu, Application of factorial and response surface methodology in modern experimental design and optimization, Crit. Rev. Anal. Chem. 36 (2006) $141-151$.

[12] A.P.M. Tavares, R.O. Cristóvão, J.M. Loureiro, R.A.R. Boaventura, E A. Macedo, Application of statistical experimental methodology to optimize reactive dye decolourization by commercial laccase, J. Hazard. Mater. 162 (2009) 1255-1260.

[13] M. Li, C. Feng, Z. Zhang, R. Chen, Q. Xue, C. Gao, N. Sugiura, Optimization of process parameters for electrochemical nitrate removal using Box-Behnken design, Electrochimica Acta 56 (2010) 265-270

[14] M. Eisapour, A. Keshtkar, M.A. Moosavian, A. Rashidi, Bioleaching of uranium in batch stirred tank reactor: process optimization using Box-Behnken design, Annals of Nuclear Energy 54 (2013) 245-250.

[15] APHA, Standard Methods for the Examination of Water and Wastewater, 17 ed., Washington, D.C., 1989.

[16] L.A. Ioannou, C. Michael, N. Vakondios, K. Drosou, N.P. Xekoukoulotakis, E. Diamadopoulos, D. Fatta-Kassinos, Winery wastewater purification by reverse osmosis and oxidation of the concentrate by solar photo-Fenton, Sep. Purif. Technol. 118 (2013) 659-669.

[17] B.S. Souza, F.C. Moreira, M.W.C. Dezotti, V.J.P. Vilar, R.A.R Boaventura, Application of biological oxidation and solar driven advanced oxidation processes to remediation of winery wastewater, Cat. Today 209 (2013) 201-208.

[18] J.P. Maran, S. Manikandan, K. Thirugnanasambandham, C.V. Nivetha, R. Dinesh, Box-Behnken design based statistical modeling for ultrasound-assisted extraction of corn silk polysaccharide, Carbohydrate Polym. 92 (2013) 604-611.

[19] B. Lodha, S. Chaudhari, Optimization of Fenton-biological treatment scheme for the treatment of aqueous dye solutions, J. Hazard. Mater. 148 (2007) 459-466.

[20] P. Bautista, A.F. Mohedano, M.A. Gilarranz, J.A. Casas, J.J. Rodriguez, Application of Fenton oxidation to cosmetic wastewaters treatment, J. Hazard. Mater. 143 (2007) 128-134.

[21] J.H. Ramirez, C.A. Costa, L.M. Madeira, Experimental design to optimize the degradation of the synthetic dye Orange II using Fenton's reagent, Catal. Today 107-108 (2005) 68-76.

[22] V.J.P. Vilar, T.F.C.V. Silva, M.A.N. Santos, A. Fonseca, I. Saraiva, R.A.R. Boaventura, Evaluation of solar photo-Fenton parameters on the pre-oxidation of leachates from a sanitary landfill, Solar Energy 86 (2012) 3301-3315.

[23] G. Hodaifa, J.M. Ochando-Pulido, S. Rodriguez-Vives, A. Martinez-Ferez, Optimization of continuous reactor at pilot scale for olive-oil mill wastewater treatment by Fenton-like process, Chem. Eng. J. 220 (2013) 117-124.

[24] R. Maciel, G.L. Sant'Anna Jr., M. Dezotti, Phenol removal from high salinity effluents using Fenton's reagent and photo-Fenton reactions, Chemosphere 57 (2004) 711-719.

[25] K.H. Chan, W. Chu, Model applications and mechanism study on the degradation of atrazine by Fenton's system, J. Hazard. Mater. 118 (2005) 227-237.

[26] M.C. Lu, Y.F. Chang, I.M. Chen, Y.Y. Huang, Effect of chloride ions on the oxidation of aniline by Fenton's reagent, J. Environ. Manag. 75 (2005) 177-182.

[27] M.D.G. Luna, R.M. Briones, C.C. Su, M.C. Lu, Kinetics of acetaminophen degradation by Fenton oxidation in a fluidized-bed reactor, Chemosphere 90 (2013) 14441448

[28] S.K. Leong, N.A.A. Bashah, Kinetic study on COD removal of palm oil refinery effluent by UV-Fenton, APCBEE Procedia 3 (2012) 6-10.

[29] M.S. Lucas, J.A. Peres, Removal of COD from olive mill wastewater by Fenton's reagent: kinetic study, J. Hazard. Mater. 168 (2009) 1253-1259. 